doi.org/10.51891/rease.v7i8.1885

\title{
ATENÇÃO FARMACÊUTICA NO TRATAMENTO DE TUBERCULOSE
}

\author{
Monique Teixeira Giacometti ${ }^{1}$ \\ Leonardo Guimarães de Andrade² \\ Fabiana Sousa Pugliese ${ }^{3}$ \\ Michel Santos da Silva ${ }^{4}$
}

RESUMO: A Tuberculose (TB) Peste branca ou como é popularmente conhecida, a tuberculose surgiu no continente africano há pelo menos 70.000 anos, acompanhou humanos na evolução e processo de expansão pelo planeta, mesmo hoje em dia considerada uma ameaça para à saúde. A TB é uma doença infecciosa crônica granulomatosa causada por bactérias do grupo das microbactérias. É importante ressaltar que existem microbactérias que podem causar tuberculose e outras que não podem. As principais causadoras são, da mais importante para a menos: tubercle bacillus, Mycobacterium bovis e Mycobacterium africanum. É considerada a doença mais infecciosa e mortal do mundo, sendo responsável por mais de 04 mil mortes diárias no mundo todo, de acordo com a Organização Mundial da Saúde (OMS).Embora afete outros órgãos e / ou sistemas, é uma doença infecciosa e contagiosa que atinge principalmente os pulmões. As formas extrapulmonares que afetam outros órgãos além dos pulmões são mais comuns entre as pessoas com HIV, especialmente aquelas com sistema imunológico enfraquecido. No Brasil, a doença é um grave problema de saúde pública com profundas raízes sociais. A epidemia de HIV e a existência de bacilos resistentes a medicamentos complicaram a situação. Todos os anos, são notificados cerca de 70.000 novos casos e cerca de 4.500 mortes por tuberculose.

Palavras- chave: Atenção farmacêutica . Tuberculose. Tratamento

\section{INTRODUÇÃO}

Segundo os conhecimentos atuais, com base em evidências arqueológicas e históricas, admite-se que o primeiro caso de infecção tuberculosa humana foi a "peste branca", que ocorreu em múmias no Egito e tem uma história de mais de 5.000 anos. Além de tecidos contendo DNA de Mycobacterium tuberculosis, C. Ele também mostra anormalidades típicas de TB envolvendo o corpo vertebral (doença de Pott). No entanto, os membros do complexo Mycobacterium tuberculosis podem incluir não

\footnotetext{
${ }^{1}$ Graduação em Farmácia pela Universidade Iguaçu - Faculdade de Ciências Biológicas e da Saúde. Email: monique.r8.giacometti@gmail.com.

${ }^{2}$ Enfermeiro/odontologia- universidade Iguaçu.

3 Farmacêutica

${ }^{4}$ Biólogo
} 
apenas Mycobacterium tuberculosis, mas também suas variantes Mycobacterium África, Mycobacterium Canada e Mycobacterium bovis, tenham ancestrais africanos comuns há 35.000-15.00o anos (HIJJAR e PROCÓPIO, 2006).

IMAGEM r:_Pessoa com tuberculose

\section{TUBERCULOSIS}

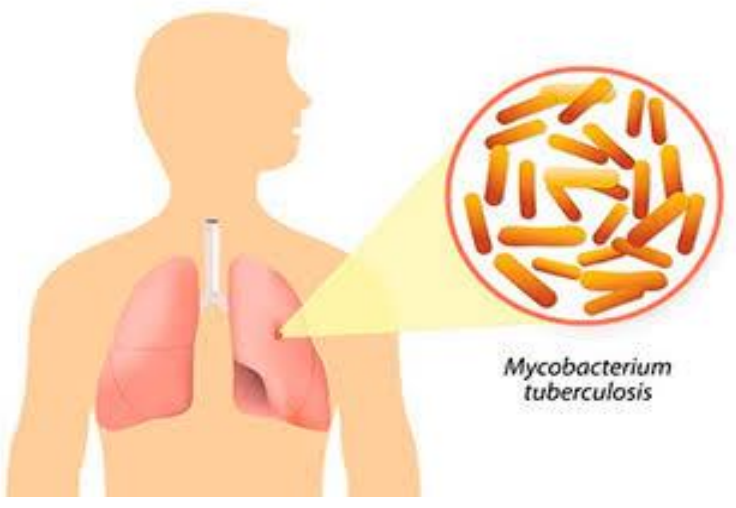

Fonte: http://www.microbiologia.ufrj.br/portal/index.php/pt/graduacao/informe-da-graduacao/438tuberculose-panorama-geral-e-a-situacao-no-brasil

A tuberculose (TB) não tem bandeira nacional, uniforme ou domicílio. Desde que se tornou bípede, está na humanidade há muito tempo. Existem relatos de tuberculose em ossos humanos pré-históricos encontrados na Alemanha, com uma história que remonta a 8.00o aC (aC). Tuberculose espinhal e esquelética também foram encontradas em ossos egípcios que datam de 2500 a.C. Embora a descrição clínica da morfologia pulmonar possa ser confundida com outras doenças, a antiga literatura hindu e chinesa descreve imagens de doenças pulmonares muito semelhantes à tuberculose (HIJJAR e PROCÓPIO, 2006).

Conforme o caráter nômade da tribo diminuiu, aglomerados e aldeias se formaram, a doença (possivelmente tuberculose) tornou-se mais perceptível e conhecida. Uma vez que a tuberculose é transmitida de pessoa para pessoa através do ar (a infecção é transmitida pelo ar), quanto mais pessoas em uma área fechada, maior a possibilidade de contaminação.

Em algumas civilizações antigas, males incluindo tuberculose eram considerados o resultado de punição divina. Só em XXX aC Hipócrates da Grécia percebeu que a 
tuberculose era uma doença natural e, devido às suas características de exaustão física, foi chamada de Tisica (do grego phthisikos, que trazia o consumo).

No século XX, a tuberculose caracterizava-se por uma elevada taxa de mortalidade, principalmente até o final da década de 1940, a partir da qual passaram a ser utilizados medicamentos para o tratamento da doença. Foi apontada como uma das principais causas de morte na capital, geralmente superada por diarreia e pneumonia, estima-se que durante este período, a tuberculose foi aproximadamente responsável por Io\% dos óbitos que ocorreram na cidade de São Paulo.

Era no século XVIII e a tuberculose, que representava a expressão física dos sentimentos, era conhecida como doença da paixão nos campos artísticos e literários. Nos países europeus, a imagem da TB está relacionada à sensibilidade à arte, ao amor e ao refinamento emocional, e se tornou uma valiosa forma de estética no século XIX. Em alguns grupos, gostar ou se tornar "tuberculose" é um símbolo de distinção, que há muito influencia o vestuário, a vida, a dieta e os padrões sociais europeus. No entanto, no final do século 19, a imagem da tuberculose foi reconstruída na Europa. A noção de romance foi substituída pela compreensão da sociedade sobre essa doença, que tem maior incidência entre a classe trabalhadora (GONÇALVES, 2000).

Em meados do século XIX e no início do século XX, a tuberculose era considerada um "mal social" que afetava principalmente as classes mais pobres, constituindo um grande problema. Outro conceito de doença, a depravação do indivíduo (mal social), reúne conceitos que definem o comportamento social (estilo de vida) e as condições de vida (moradia, saneamento, trabalho) relacionados à doença. Nesse caso, a culpa é do indivíduo, pois a doença é resultado de maus hábitos, falta de higiene e condições de vida. (GONÇALVES, 200o).

\section{DESENVOLVIMENTO}

Era dia 24 de março de 1882 quando o médico, patologista e bacteriogista alemão, Heinrich Hermann Robert Koch, anunciava a identificação do bacilo causador da tuberculose. 


\section{IMAGEM:_Robert Koch}

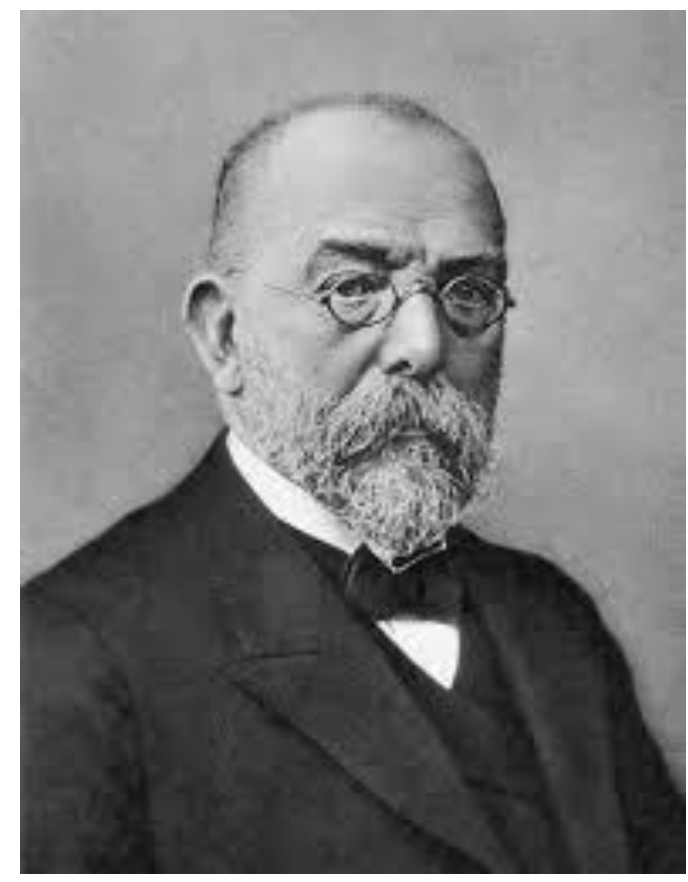

Fonte: https://pt.m.wikipedia.org/wiki/Robert_och

"Robert Koch queria agora evidenciar o causador da tísica através de testes com

animais e análise microscópica. Em agosto de $188 \mathrm{I}$, iniciou suas pesquisas: infectou duas cobaias com material tuberculoso e esperou que estas adoecessem. Paralelamente, preparava amostras, coloria e examinava-as no microscópio.” ( $\mathrm{dw}$, 202I, 3).

Robert Koch sempre usa novas técnicas de coloração para tentar tornar visíveis as coisas que as pessoas nunca viram antes. No $271^{\circ}$ trabalho de preparação, o pesquisador encontrou o que procurava: uma fina bactéria em forma de bastonete com formas curvas e redemoinhos. Ele conseguiu cultivar esses micro-organismos em nutrientes. No final, ele encontrou a última evidência de que precisava: essa cultura que surgiu fora do hospedeiro é a causa da tuberculose. No meio de algumas tentativas de vários médicos pelo planeta, a descoberta de Robert foi a primeira e mais importante para o combate á tuberculose.

"A tuberculose é uma das doenças mais antigas da humanidade, causada por bactérias pertencentes ao complexo Mycobacterium tuberculosis. Segundo a Organização Mundial de Saúde, cerca de roo milhões de pessoas são infectadas pelo M. tuberculosis a cada ano e, nos países subdesenvolvidos, entre 30\% e 60\% dos adultos 
estão infectados" (KOZAKEVICH e SILVA, 2015, PI). Entre essas pessoas infectadas, 8 o a Io milhões de pessoas sofrerão desta doença ao longo da vida, e cerca de metade delas serão infecciosas. O número completa 3 milhões de mortes conhecidas e confirmadas a cada ano. O Mycobacterium tuberculosis é transmitido pela tosse, espirro, fala e inalação de gotículas infecciosas espalhadas no ar por pacientes infectados.

Um informe da OMS em 2006 estima que houve nove milhões de casos no mundo. Isto corresponde a um coeficiente de incidência de 140/100.00o habitantes. Nas Américas, o Brasil é o que mais apresenta Casos de notificação - cerca de 80.00o a 90.00o e aproximadamente 15.000 novos casos por ano de abandono tratamento. Brasil e Peru são 50\% de todos os casos na América.

\section{ALEXANDER FLEMING E O PRIMEIRO ANTIBIÓTICO}

Alexander Fleming foi biólogo, botânico, médico, microbiólogo e farmacologista britânico. O médico britânico Alexander Fleming voltou ao mundo depois da Primeira Guerra mundial e sonhou: pesquisar uma forma de reduzir o sofrimento dos soldados que tinham suas feridas infectadas, impondo dor e por tantas vezes um processo ainda mais acelerado em direção à morte.

Em 1928, ele voltou ao St. Mary's Hospital, em Londres, para estudar a bactéria Staphylococcus aureus, responsável por abcessos em feridas abertas causados por armas de fogo. Ele estudou tanto que um dia ficou tão exausto que decidiu se dar alguns dias de folga de presente. Saiu, deixando o recipiente de vidro no laboratório, onde a cultura bacteriana não foi supervisionada. Essa negligência fez com que ele encontrasse um copo sem tampa ao retornar, que estava exposto e contaminado com mofo do próprio ambiente.

Quando ele olhou dentro do vidro, percebeu que não havia estafilococos em todos os lugares onde o molde se formou, e ele jogaria fora todos os materiais. Ele concluiu que o mofo é derivado do fungo Penicillium e sua função é secretar uma substância que destrói bactérias.

Embora por acaso o primeiro antibiótico da história da humanidade tenha sido criado - a penicilina, para muitos cientistas esta é uma das descobertas mais 
importantes da história humana. Para eles, a medicina mudou apenas dos antibióticos para a ciência real. Antes deles, essa era uma boa maneira de diagnosticar doenças infecciosas. Quanto ao tratamento e reabilitação, apenas explicações religiosas podem compreender ou fornecer ajuda.

Com a descoberta de Alexander Fleming, a porta para um novo mundo se abriu, e uma grande indústria passou a se dedicar à produção de penicilina e outros antibióticos, proporcionando assim uma vida com qualidade para as pessoas que sofrem de tuberculose e outras doenças infecciosas.

A penicilina só foi usada na Inglaterra em 1938 por Ernst B. Chain e Howard W. Embora pouco depois da descoberta de Fleming, as pessoas estivessem A eficácia criou uma onda de desconfiança, mas isso não impediu os cientistas médicos de continuarem a estudar a substância. Guerra Mundial e a necessidade crescente de ajudar os feridos, o patologista Florey, da Universidade de Oxford (Florey) O médico conduziu pessoalmente pesquisas sobre a penicilina, retomou o cultivo do mofo de Fleming e extraiu o pó marrom dele. A substância foi testada em 80 tipos de bactérias e provou sua eficácia contra microrganismos e sua inércia para os glóbulos brancos.

Em I940, no Reino Unido, a penicilina foi usada no primeiro paciente humano, um policial, vítima de grave infecção sanguínea. A partir de então, o mundo começou a entender e desfrutar de armas vitais para a vida e sobrevivência.

Mesmo assim até mesmo hoje em dia se vê casos de tuberculose por conta de as prevenções não serem Ioo\% efetivas. Aqui vai uma tabela de 2011 feito pela organização mundial de saúde (OMS

TABELA r:_Tabela feita pela OMS

\begin{tabular}{|l|l|l|l|}
\hline PAÍS & $\begin{array}{l}\text { População do país } \\
(201 \mathrm{I})\end{array}$ & $\begin{array}{l}\text { Estimativas de casos } \\
\text { em 20II }\end{array}$ & $\begin{array}{l}\text { Números de casos por } \\
\text { Ioo mil habitantes }\end{array}$ \\
\hline Afeganistão & 32.358 & $61 \mathrm{mil}$ & $\begin{array}{l}\text { I89 } \\
\text { 14 }{ }^{\circ} \text { lugar }\end{array}$ \\
\hline África do Sul & 50.460 & $500 \mathrm{mil}$ & $\begin{array}{l}993 \\
\mathrm{I}^{\circ} \text { posição }\end{array}$ \\
\hline Bangladesh & 150.494 & $340 \mathrm{mil}$ & $\begin{array}{l}225 \\
\mathrm{II}^{\circ} \text { posição }\end{array}$ \\
\hline Brasil & 196.655 & $83 \mathrm{mil}$ & $\begin{array}{l}42 \\
22\end{array}$ \\
\hline
\end{tabular}




\begin{tabular}{|c|c|c|c|}
\hline Camboja & 14.305 & 6r mil & $\begin{array}{l}424 \\
4^{\circ} \text { posição }\end{array}$ \\
\hline China & 1.347 .565 & I milhão & $\begin{array}{l}74 \\
21^{\circ} \text { posição }\end{array}$ \\
\hline Congo & 67.758 & $220 \mathrm{mil}$ & $\begin{array}{l}327 \\
6^{\circ} \text { posição }\end{array}$ \\
\hline Etiópia & 84.734 & $220 \mathrm{mil}$ & $\begin{array}{l}25^{8} \\
9^{\circ} \text { posição }\end{array}$ \\
\hline ,Índia & 1.241 .492 & 2,2 milhões & $\begin{array}{l}\text { I8I } \\
16^{\circ} \text { posição }\end{array}$ \\
\hline Indonésia & 242.326 & $450 \mathrm{mil}$ & $\begin{array}{l}187 \\
15^{\circ} \text { posição }\end{array}$ \\
\hline Quênia & 41.610 & $120 \mathrm{mil}$ & $\begin{array}{l}288 \\
7^{\circ} \text { posição }\end{array}$ \\
\hline Moçambique & 23.930 & $130 \mathrm{mil}$ & $\begin{array}{l}548 \\
3^{\circ} \text { posição }\end{array}$ \\
\hline Mianmar & 48.337 & I8o mil & $\begin{array}{l}381 \\
5^{\circ} \text { posição }\end{array}$ \\
\hline Nigéria & 162.471 & I90 mil & $\begin{array}{l}\text { II } 8 \\
19^{\circ} \text { posição }\end{array}$ \\
\hline Paquistão & 176.745 & $410 \mathrm{mil}$ & $\begin{array}{l}231 \\
10^{\circ} \text { posição }\end{array}$ \\
\hline Filipinas & 94.852 & $260 \mathrm{mil}$ & $\begin{array}{l}270 \\
8^{\circ} \text { posição }\end{array}$ \\
\hline Rússia & 142.836 & I40 mil & $\begin{array}{l}97 \\
20^{\circ} \text { posição }\end{array}$ \\
\hline Tailândia & 64.519 & $86 \mathrm{mil}$ & $\begin{array}{l}\mathrm{I} 24 \\
\mathrm{I} 8^{\circ} \text { posição }\end{array}$ \\
\hline Uganda & 34.509 & $67 \mathrm{mil}$ & $\begin{array}{l}193 \\
13^{\circ} \text { posição }\end{array}$ \\
\hline Tanzânia & 46.218 & $78 \mathrm{mil}$ & $\begin{array}{l}169 \\
17^{\circ} \text { posição }\end{array}$ \\
\hline Vietnã & 88.722 & I8o mil & $\begin{array}{l}199 \\
12^{\circ} \text { posição }\end{array}$ \\
\hline Zimbábue & 12.754 & $77 \mathrm{mil}$ & $\begin{array}{l}603 \\
2^{\circ} \text { posição }\end{array}$ \\
\hline
\end{tabular}

FONTE: http://redeglobo.globo.com/acao/noticia/2012/12/oms-divulga-lista-dos-22-paises-maisafetados-com-tuberculose.html

\section{FIGURAS BRASILEIRAS IMPORTANTES QUE TIVERAM SUAS VIDAS TIRADAS PELA TUBERCULOSE.}

\section{Álvares de Azevedo}

Álvares de Azevedo (1831-I852) foi um poeta, escritor e contista brasileiro. Seus poemas descrevem seu mundo interior. Ele é chamado de "o poeta da dúvida". 


\section{Augusto dos Anjos}

Augusto dos Anjos (I884-1914) foi um poeta brasileiro, considerado um dos mais importantes poetas de sua época. Embora revele o fundamento do simbolismo em seus poemas, retratando o sabor da morte, a dor e o uso de metáforas, ele é considerado o poeta mais importante do pré-modernismo.

\section{Castro Alves}

Castro Alves (1847-1871) foi um poeta brasileiro e representante da terceira escola romântica do Brasil. O poeta escravo expressou sua indignação com os graves problemas sociais de sua época em seus poemas. É patrono do $7^{\circ}$ anfitrião da Academia Brasileira de Letras.

\section{Casimiro de Abreu}

Casimiro de Abreu (I839-1860) foi um poeta brasileiro, e seu livro "Meus Oito Anos" foi a segunda geração do romantismo, um dos poemas mais populares da literatura brasileira que se destaca.

Em I853 foi para Lisboa. Foi durante este período que escreveu a maior parte dos poemas do seu único livro "Primaveras". É patrono do sexto presidente da Academia Brasileira de Letras.

\section{José de Alencar}

José de Alencar (1829-ı877) foi um romancista, dramaturgo, jornalista, advogado e político brasileiro. É um dos maiores representantes da corrente literária hindu e o principal romancista brasileiro no período romântico. Em seus romances, "Iracema" e "Senhora" se destacam.

\section{SINTOMAS DA TUBERCULOSE}

- Dores no peito

- Tosse

- Cansaço excessivo

- Perda de peso

- Febre baixa

- Sudorese noturna

- Perda de apetite

Além dos pulmões, a tuberculose também pode afetar os rins, ossos, meninges e outros órgãos:

- Pleura (na membrana que cobre os pulmões); 
- Pele

- cérebro;

- Gânglio (afetando os nódulos linfáticos / nódulos linfáticos);

- osso;

- Urina

Para os casos de tuberculose pulmonar, também há sensação de dor torácica, cansaço (muito associado à dor e ao comprometimento pulmonar) e dispnéia (ou seja, dificuldade para respirar). A febre é um sintoma não tão frequente, porém quando se manifesta é preferencialmente no período da tarde. O indivíduo com tuberculose também apresenta a tendência em emagrecer repentinamente e sem causa aparente.

É importante saber que há muitos casos nos quais não há manifestação de nenhum sintoma, visto que não existe tuberculose apenas na forma pulmonar, e essa infecção pode ser instalar em outros órgãos/ estruturas, tais como ossos, linfonodos, sistema nervoso, intestino e sistema geniturinário.

\section{TRANSMISSÃO}

Estima-se que cerca de $30 \%$ da população mundial esteja infectada, mas isso não significa que todas essas pessoas sofrerão com a doença.

Os indivíduos vivem com bactérias porque não podem eliminá-las ou destruí-las. Assim que o foco é reativado, eles se tornam infecciosos.

Quando o bacilo não é bloqueado e se divide, a doença se desenvolve, destrói as células e causa uma forte resposta inflamatória em vários tecidos circundantes. Os pulmões respondem produzindo muco e, em seguida, ocorre uma tosse produtiva.

A transmissão da tuberculose é classificada como transmissão direta é por via aérea, que ocorre devido à inalação de partículas sólidas ou líquidas em suspensão no ar, meio gasoso (aerossol), ou seja, através do contágio de pessoa para pessoa. Portanto, a transmissão ocorrerá durante a fala, espirros ou tosse, e as pessoas com tuberculose ativa lançarão para o ar partículas contendo bactérias; sendo que essas últimas formas de contaminação são as mais prováveis, visto que há certo movimento de propulsão vindo do pulmão. Essas gotículas de saliva expelidas ficam em suspensão no ambiente 
na forma de aerossóis, sendo que dessa forma podem ser facilmente inaladas por outras pessoas, gerando a contaminação. Em ambientes fechados e não arejados, o bacilo pode sobreviver por um período de tempo de até 8 horas.

Pessoas com esfregaço de escarro positivo (bactérias tuberculosas no escarro) podem infectar uma média de io a is pessoas durante o ano em que vivem na comunidade.

Vale ressaltar que bactérias presas em roupas, lençóis, óculos e outros objetos não se dispersam facilmente em aerossóis, portanto, não desempenham um papel importante na disseminação da tuberculose.

\section{TRATAMENTO}

O tratamento da tuberculose visa curar e reduzir rapidamente a propagação da doença. Para tanto, os medicamentos utilizados devem ser capazes de reduzir rapidamente a população bacteriana (transmissão de interferência), prevenir a seleção de cepas naturalmente resistentes (prevenir resistência durante o tratamento) e desinfetar as lesões (prevenir a recorrência da doença) ... Embora a eficácia do programa anti-tuberculose seja de até 95\%, a eficácia do tratamento (em pacientes que curam após o fim do tratamento em circunstâncias normais) varia dependendo da localização e é de cerca de 70\% (50-90 \%) na média nacional. Um dos motivos associados à baixa eficácia é a falta de adesão, que pode ocorrer em três níveis: abandono de tratamento (o paciente para de usar todos os medicamentos); uso incorreto dos medicamentos (paciente usa apenas alguns dos medicamentos prescritos) e uso irregular de medicamentos (paciente não faz uso constante do medicamento).

O tratamento da tuberculose dura pelo menos seis meses, é gratuito, está disponível no Sistema Único de Saúde (SUS) e deve ser preferencialmente feito, em regime de Tratamento Diretamente Observado (TDO). Quatro medicamentos são usados no regime básico para o tratamento da tuberculose: rifampicina, isoniazida, pirazinamida e etambutol (BARREIRA e GRANGEIRO, 2007).

O TDO é considerado a principal ação de apoio e acompanhamento no tratamento do paciente com tuberculose, e tem como premissa o comprometimento dos 
profissionais de saúde e a atuação humanizada. Além de estabelecer um vínculo entre profissionais de saúde e pacientes com TB, o TDO também inclui a observação de pacientes sob a supervisão de profissionais de saúde ou outros profissionais treinados (como profissionais de assistência social, etc.).

Idealmente, o TDO deve ser realizado em todos os dias úteis da semana. O local e a hora do TDO devem ser negociados com o pessoal e os serviços médicos. É necessário informar claramente aos pacientes com $\mathrm{TB}$ as características da doença e o tratamento que irão receber. Os profissionais de saúde devem informá-lo sobre a duração e o cronograma do tratamento e do uso de medicamentos, incluindo os benefícios do uso rotineiro, as possíveis consequências do uso irregular e os eventos adversos relacionados.

Todas as pessoas que recebem o tratamento correto podem ser curadas da doença. Nas primeiras semanas de tratamento o paciente sente-se melhor, portanto, independentemente da melhora dos sintomas, o tratamento deve ser realizado até o final do tratamento e sob a orientação de um profissional de saúde. É importante lembrar que o tratamento irregular pode complicar a doença e levar ao desenvolvimento de tuberculose resistente aos medicamentos.

\subsection{ATENÇÃO FARMACÊUTICA NO TRATAMENTO DA TUBERCULOSE}

A tuberculose é uma doença que se tem uma grande dificuldade de adesão ao tratamento, devido a essa dificuldade, o profissional farmacêutico foi inserido na equipe multidisciplinar para atuar na Atenção Básica de Saúde, juntamente com médicos, equipes de enfermagem e serviço social. Concluiu-se que a Assistência Farmacêutica, presta atendimento de qualidade ao paciente com tuberculose, orientando no esquema terapêutico, explicando a maneira correta de se administrar o medicamento, informando que é um tratamento longo e precisa ser feito até o fim, para que não cause reincidências e sim Ioo\% da cura.

O cuidado com medicamentos é uma prática em que os profissionais são responsáveis pelas necessidades do paciente relacionadas ao uso de medicamentos e obtenção de compromissos. Fatos comprovam que o trabalho do farmacêutico pode 
melhorar a adesão do paciente aos regimes de tratamento medicamentoso, reduzir o custo do sistema de saúde, monitorar reações adversas e interações medicamentosas, ter como objetivo o uso racional de medicamentos (URM) e melhorar a qualidade de vida dos pacientes. A assistência farmacêutica (ATF) é uma prática profissional para pacientes, desenvolvida por farmacêuticos e outros profissionais de saúde. Portanto, o objetivo deste estudo é relatar a atividade do tratamento medicamentoso para pacientes com ILTB recebendo quimioterapia.

\section{CONCLUSÃO}

Embora notória durante o século XX, a redução da mortalidade por TB não foi mantida nas últimas décadas. Dentre as razões para tal situação destacam-se: a desigualdade social e seus determinantes, o advento da AIDS, a multirresistência do bacilo causador da moléstia, o envelhecimento da população.

No entanto, a tuberculose é uma doença quase sempre curável com as medidas eficazes de prevenção e tratamento. Felizmente, frente à atual conjuntura, ações têm sido propostas com o propósito de reverter tal contexto, como o fortalecimento da estratégia de supervisão do tratamento (TS) e a capacitação de profissionais para diferentes níveis de atendimento médico para pacientes com doenças e pesquisa diagnóstica para pacientes sintomáticos respiratórios, problemas do sistema respiratório, ou seja, tosse mais do que em três semanas. Essas iniciativas representam estratégias eficazes para a detecção precoce de indivíduos com tuberculose, a pronta instituição terapêutica e o menor surgimento de resistência. Três aspectos diferentes (humanitário, saúde Pública e econômico) que atuam juntos para o controle da Tuberculose global, e assim pode tornar as pessoas mais otimistas em face da nova tuberculose e Métodos de pesquisa interdisciplinar da doença.

\section{REFERÊNCIAS}

Por: DA REDAÇÃO VEJA 6 de maio 2016 Tuberculose surgiu há 70 ooo anos; e evoluiu com

o homem: https://www.google.com.br/url?sa=t\&source=web\&rct=j\&url=https://veja.abril.co $\mathrm{m} . \mathrm{br} /$ ciencia/tuberculose-surgiu-ha-7o-ooo-anos-e-evoluiu-com-o- 
homem/amp/\&ved=2ahUKEwivgH72tPwAhUfrsUCHaW \&usg=AOvVawow5yDVuo6Mv2PrljRaKHRa\&ampcf $=\mathrm{I}$

MACIEL, MARINA. MENDES, PLÍNIO. GOMES, ANDRÉIA. BATISTA, RODRIGO. A HISTÓRIA DA TUBERCULOSE NO BRASIL: OS MUITOS TONS (DE CINZA) DA MISÉRIA. 20I2. 5 f. Recebido do Departamento de Medicina e Enfermagem da Universidade Federal de Viçosa (UFV), Viçosa, M8G, e do Curso de Graduação em Medicina do Centro Universitário Serra dos Órgãos (UNIFESO), Rio de Janeiro, RJ. Disponível em: http://files.bvs.br/upload/S/r679IOIO/2012/vion3/a2886.pdf. Acessado em 27/05/2021.

HIJJAR, MIGUEL. PROCÓPIO, MARIA. TUBERCULOSE EPIDEMIOLOGIA E CONTROLE NO BRASIL. 2006. 13f. Editorial: A Tuberculose Nos Primeiros Anos do Século XXI. Disponível em: file:///C:/Users/isabella.santos/Downloads/9201-32175-1-PB.pdf

KOZAKEVICH, GABRIEL. SILVA, ROSEMERE. TUBERCULOSE: REVISÃO DE LITERATURA. 2015. 47f. Arquivos Catarinenses de medicina. Disponível em: file:///C:/Users/isabella.santos/Downloads/46-86-I-SM.pdf

POR REVISTA PRESENÇA, Assistência farmacêutica a pacientes com tuberculose pulmonar: uma revisão integrativa, Disponível em: http://sistema.celsolisboa.edu.br/ojs/index.php/numerohum/article/view/ıo3 REDE GLOBO, 22 PAÍSES MAIS AFETADOS COM TUBERCULOSE, 08/12/2012, Disponível em: http://redeglobo.globo.com/acao/noticia/2012/12/omsdivulga-lista-dos-22-paises-mais-afetados-com-tuberculose.html

POR SALÃO DE ENSINO E DE EXTENSÃO, UMA EXPERIÊNCIA NA ATENÇÃO FARMACÊUTICA À PACIENTES COM TUBERCULOSE LATENTE, Disponível em: https://online.unisc.br/acadnet/anais/index.php/salao_ensino_extensao/article/v iew/IOII4

EBIOGRAFIA, Disponível em: https://www.ebiografia.com/

BARREIRA, DRAURIO. GRANGEIRO, ALEXANDRE. AVALIAÇÃO DAS ESTRATÉGIAS DE CONTROLE DA TUBERCULOSE NO BRASIL. 2007. $4 \mathrm{f}$. Programa Nacional de Controle da Tuberculose. Secretaria de Vigilância em Saúde. Ministério da Saúde. Brasília, DF, Brasil. IINúcleo de Investigação de Condições de Vida e Situação de Saúde. Instituto de Saúde. Secretaria de Estado da Saúde de São Paulo. São Paulo, SP, Brasil. Rev. Saúde Pública vol.4I suppl.ı São Paulo Sept. 2007. Disponível em: https://www.scielo.br/scielo.php?pid=Soo3489102007000800002\&script $=$ sci_arttext $\&$ tlng $=$ pt

CSS SAÚDE IMAGENS DA PESTE BRANCA: MEMÓRIA DA TUBERCULOSE, Disponível em: http://www.ccs.saude.gov.br/peste-branca/tbhistoria.php 
Dr. ANTÔNIO COSTA SAUDE BEM ESTAR O QUE É TUBERCULOSE?, Disponível em: https://www.saudebemestar.pt/pt/medicina/pneumologia/tuberculose/

FUNDAÇÃO ATUALPHO DE PAIVA, PERSONALIDADES HISTÓRICAS MORTAS PELA TUBERCULOSE. Disponível em: https://www.fundacaoataulphodepaiva.com.br/blog/personalidades-historicasmortas-pela-tuberculose/

EQUIPE VERITÁ, Tuberculose: Quais são os primeiros sintomas da tuberculose e o que fazer? Disponível em: https://www.veritadiagnosticos.com.br/tuberculosequais-sao-os-primeiros-sintomas-da-tuberculose-e-o-que-fazer/

DEPARTAMENTO DE DOENÇAS DE CONDIÇÕES CRÔNICAS E INFECÇÕES SEXUALMENTE TRANSMISSÍVEIS MINISTÉRIO DA SAÚDE, TUBERCULOSE. Disponível em: http://www.aids.gov.br/pt-br/o-que-etuberculose

POR BEP SAÚdE, TUBERCULOSE: TRANSMISSÃO, SINTOMAS, PREVENÇÃO. Disponível em: https://beepsaude.com.br/tuberculose-transmissaosintomas-prevencao/ 